\title{
Article
}

\section{Transgene CpNAC68 from Wintersweet (Chimonanthus praecox) Improves Arabidopsis Survival of Multiple Abiotic Stresses}

\author{
Jie Lin ${ }^{1,2}$, Daofeng Liu ${ }^{1}$, Xia Wang ${ }^{1}$, Sajjad Ahmed ${ }^{2}$, Mingyang Li ${ }^{1}$, Nik Kovinich ${ }^{2, *}$ and Shunzhao Sui ${ }^{1, *}$ \\ 1 Chongqing Engineering Research Center for Floriculture, Key Laboratory of Horticulture Science for \\ Southern Mountainous Regions of Ministry of Education, College of Horticulture and Landscape \\ Architecture, Southwest University, Chongqing 400715, China; 1j0215@yorku.ca (J.L.); \\ liu19830222@163.com (D.L.); wx221069@email.swu.edu.cn (X.W.); limy@swu.edu.cn (M.L.) \\ 2 Department of Biology, Faculty of Science, York University, Toronto, ON M3J 1P3, Canada; \\ ahmed80@yorku.ca \\ * Correspondence: kovinich@yorku.ca (N.K.); sszcq@swu.edu.cn (S.S.); Tel.: +1-416-736-2100 (N.K.); \\ $+86-23-6825-0086$ (S.S.)
}

Citation: Lin, J.; Liu, D.; Wang, X.; Ahmed, S.; Li, M.; Kovinich, N.; Sui, S. Transgene CPNAC68 from

Wintersweet (Chimonanthus praecox) Improves Arabidopsis Survival of Multiple Abiotic Stresses. Plants 2021, 10, 1403. https://doi.org/10.3390/ plants10071403

Academic Editor: Juan Barceló

Received: 7 June 2021

Accepted: 5 July 2021

Published: 9 July 2021

Publisher's Note: MDPI stays neutral with regard to jurisdictional claims in published maps and institutional affiliations.

Copyright: (c) 2021 by the authors. Licensee MDPI, Basel, Switzerland. This article is an open access article distributed under the terms and conditions of the Creative Commons Attribution (CC BY) license (https:// creativecommons.org/licenses/by/ $4.0 /)$.

\begin{abstract}
The NAC (NAM, ATAFs, CUC) family of transcription factors (TFs) play a pivotal role in regulating all processes of the growth and development of plants, as well as responses to biotic and abiotic stresses. Yet, the functions of NACs from non-model plant species remains largely uncharacterized. Here, we characterized the stress-responsive effects of a NAC gene isolated from wintersweet, an ornamental woody plant that blooms in winter when temperatures are low. CpNAC68 is clustered in the NAM subfamily. Subcellular localization and transcriptional activity assays demonstrated a nuclear protein that has transcription activator activities. qRT-PCR analyses revealed that CpNAC68 was ubiquitously expressed in old flowers and leaves. Additionally, the expression of CpNAC68 is induced by disparate abiotic stresses and hormone treatments, including drought, heat, cold, salinity, GA, JA, and SA. Ectopic overexpression of CpNAC68 in Arabidopsis thaliana enhanced the tolerance of transgenic plants to cold, heat, salinity, and osmotic stress, yet had no effect on growth and development. The survival rate and chlorophyll amounts following stress treatments were significantly higher than wild type Arabidopsis, and were accompanied by lower electrolyte leakage and malondialdehyde (MDA) amounts. In conclusion, our study demonstrates that CpNAC68 can be used as a tool to enhance plant tolerance to multiple stresses, suggesting a role in abiotic stress tolerance in wintersweet.
\end{abstract}

Keywords: $C p N A C 68$; transcription factor; Chimonanthus praecox; abiotic stress; cold tolerance

\section{Introduction}

Plants have evolved complex responses to mitigate the effects of abiotic stresses. These include long-term physiological adaptations, such as changes in stature and lifecycle, and rapid molecular responses that alleviate the damaging effects of stress [1]. At the genetic level, rapid responses, including the activation of transcription factors (TFs) activate or repress the expression of genes encoding antioxidant enzymes [2], cell wall-related genes [3], and TFs [4]. NAC (NAM, ATAF1/2, CUC) is one of the largest TF families and is unique to plants. NAC proteins regulate genes by directly binding specific cis-acting DNA elements to activate or repress gene expression at the transcription level $[5,6]$.

In the past decades, a growing number of NAC family genes have been identified and characterized. Most of them are widely involved in the regulation of various developmental, physiological, or stress-responsive processes. Compared with the typical helix-turn-helix structure of DNA binding, NAC TF proteins have unique domain characteristics [7]. All proteins in this family share a conserved N-terminal NAC domain, containing A, B, C, $\mathrm{D}, \mathrm{E}$ subdomains. NAC proteins function as homo- or hetero-dimers, providing multiple functions due to varying compositions of monomers. The N-terminal NAC domain has 
an abundance of positive charges that are believed to enable the one side of the protein dimer to directly bind to DNA [8]. Nuclear localization signals in the $C$ and D sub-region sequences may also be involved in binding cis-acting elements [7].

As one of the largest TF families in plants, NACs are divided into different subfamilies according to the sequence of their NAC domain. The subfamilies are NAP (NAC-like, Activated by AP3/PI), ATAF1/2 (Arabidopsis thaliana activation factor1/2), NAM (no apical meristem), and CUC (cup-shaped cotyledon). The NAP subfamily is reported to mainly regulate senescence, such as AtNAP [9], OsNAP [10], CitNAC [11], and ApNAP [12]. Functional characterization of these genes demonstrated that they are involved in leaf senescence [9,11-13]. The NAM subfamily mainly regulates the formation of apical meristems [14,15], whereas the CUC subfamily affects general growth and development [16]. The VND (vascular-related NAC-domain) subfamily may have a role in the development of secondary vascular tissues in woody plants [17-20], and specifically in mediating programmed cell death [19]. The ATAF subfamily regulates responses to biotic and abiotic stresses and can improve stress tolerance when expressed ectopically in non-host plant species [21]. For example, overexpressing $S g N A C 1$ and $S g N A C 2$ from Stylosanthes guianensis in tobacco enhanced tolerance to cold stress [22]. Moreover, ectopic expression of $\mathrm{HaNAC1}$ could augment drought stress tolerance in transgenic Arabidopsis [23].

NAC family genes are widely involved in plant growth [24], fiber development [25], lateral root development [26], fruit quality [27], ripeness of fruit [28], biotic [29] and abiotic stress responses [30], hormone responses [31], senescence [32,33], programmed cell death [34], and other physiological activities. Since the majority of NAC TFs regulate diverse processes, they are promising candidate genes in plant breeding [35]. However, research on NAC TFs has extensively focused on model plants such as A. thaliana [36], and select crop species, such as Solanum lycopersicum [37], Populus [38], Oryza sativa [39,40], Triticum aestivum [41], and Zea mays [42].

Wintersweet (Chimonanthus praecox (L.) Link) belongs to the Calycanthaceae family and is a perennial deciduous shrub. As a traditional and famous ornamental landscape plant in China, wintersweet blooms in cold winter with sweet fragrance [43]. Research on wintersweet has mainly focused on the molecular mechanisms of flower development [44], floral scent [45,46], flowering time [47], and the regulation of volatile compound [48] and flavonoid biosynthesis [49].

TFs may be involved in the regulation of different processes, including growth, flower development, metabolic pathways, and abiotic and biotic stresses [4]. In order to understand the biological functions of the NAC gene family in wintersweet, we isolated the cDNA of CpNAC68 based on transcriptome data [50]. We assessed CpNAC68 for the transcriptional activation activity, subcellular localization, and physiological functions ectopically in Arabidopsis under various abiotic stresses. The evidence shows that CpNAC68 is a NAM-type NAC TF that confers enhanced tolerance to multiple abiotic stresses.

\section{Results}

\subsection{Cloning and Sequence Analysis of CpNAC68}

We cloned the largest open reading frame (ORF) of $C p N A C 68$ from the wintersweet leaf cDNA. Sequencing revealed that it was $906 \mathrm{bp}$, encoding a predicted protein of 302 amino acids (GenBank accession MZ501790). According to software predictions, the molecular weight of CpNAC68 is $34.32 \mathrm{kDa}$, and its theoretical isoelectric point (PI) and the instability index are 5.84 and 39.63, respectively. CpNAC68 lacks an obvious signal peptide or transmembrane domain sequence, as is observed in many other NAC proteins [51]. Secondary structure prediction indicated that it contains $25.91 \% \alpha$ helix, $10.96 \%$ extended strands, $3.65 \% \beta$ turn, and $59.47 \%$ random coil. BlastP identified several characterized NAC68s from different plant species. Multiple sequence alignment showed that the N-terminal half of CpNAC68 has the conserved domain, including A, B, C, D, and E subdomains [8], while the C-terminal half is highly divergent (Figure 1A). Sequence analysis revealed that $C p N A C 68$ is a member of the NAM subfamily and shares the highest amino 
acid sequence similarity with the CmNAC68-like protein from Cinnamomum micranthum (79.67\%). A neighbor-joining (NJ) cluster tree with various characterized NACs clustered CpNAC68 with MusaNAC68, TaNAC47, and TaNAC67 (Figure 1B). All three of these genes have been identified to improve tolerance to multiple abiotic stresses.

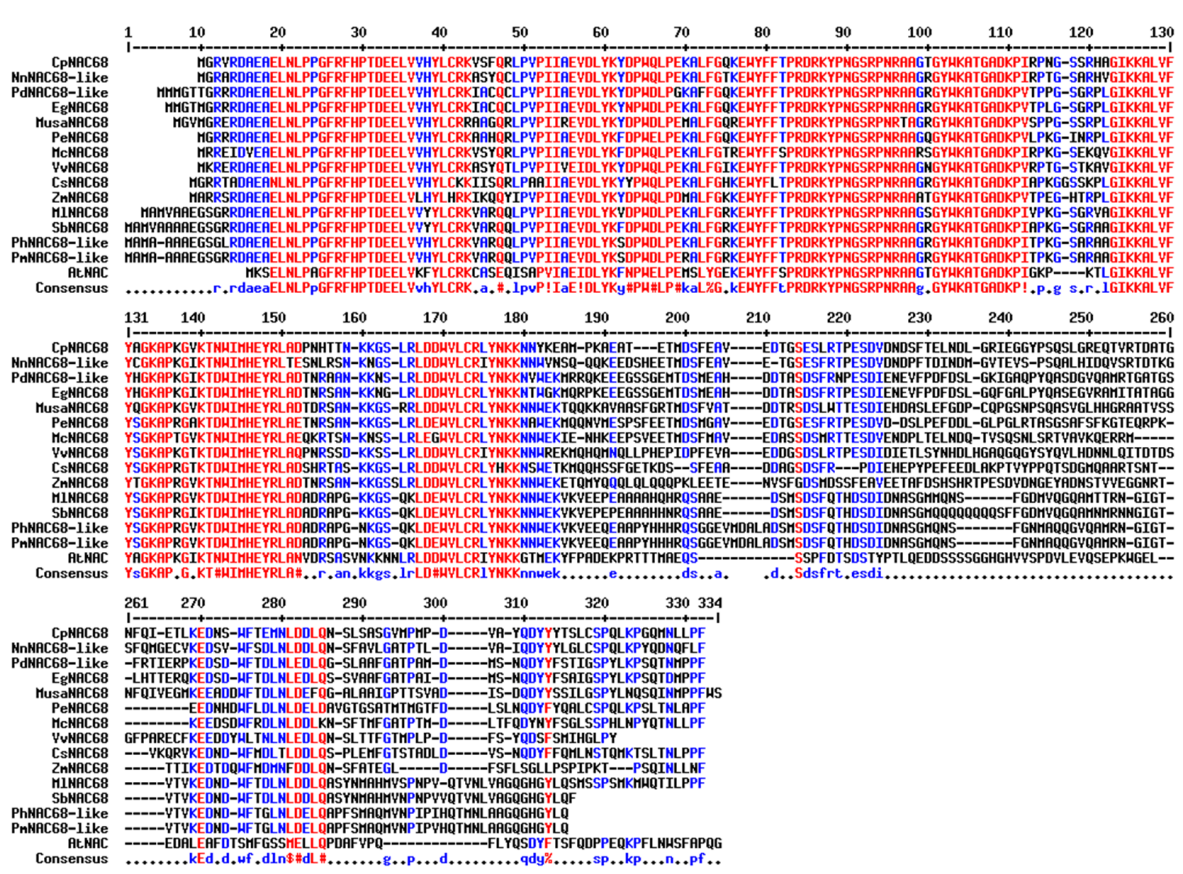

A

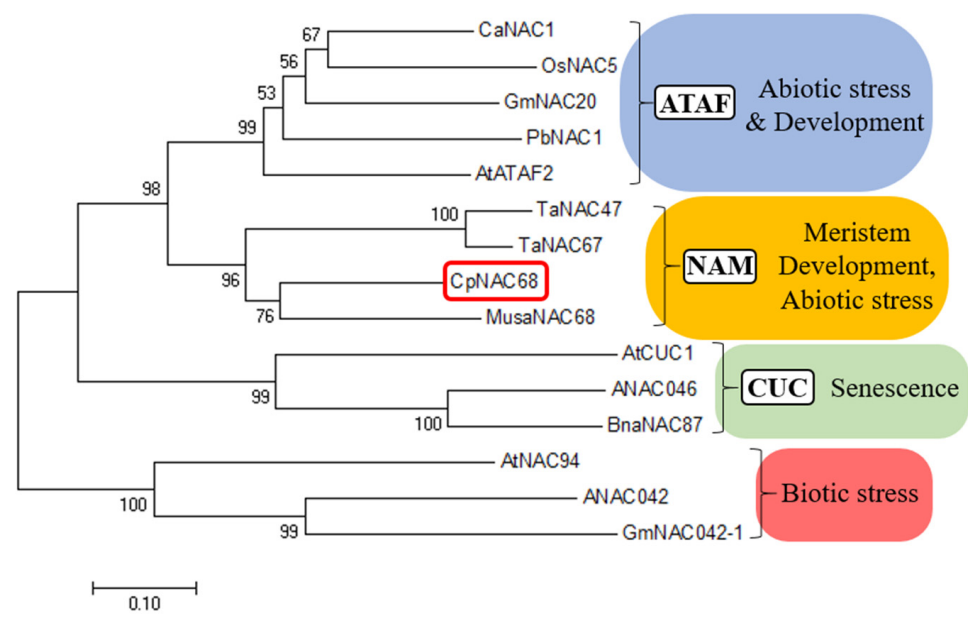

B

Figure 1. Sequence analysis of CpNAC68. (A) Multiple sequence alignment of CpNAC68 with other NAC68 TFs. The red sequence shows highly conserved subdomains. (B) Cluster analysis of CpNAC68 (indicated by a red frame) and NAC proteins from other species. Accession numbers: Nelumbo nucifera (XP_010257746.1), Phoenix dactylifer (XP_008782755.1), Elaeis guineensis (XP_010921285.1), Musa acuminata (XP_009399922.1), Phalaenopsis equestris (XP_020578930.1), Macleaya cordata (OVA03901.1), Vitis vinifera (XP_002283807.1), Crocus sativus (ABU40779.1), Zostera marina (KMZ65511.1), Miscanthus lutarioriparius (AIS74871.1), Sorghum bicolor (XP_002458677.1), Panicum hallii (XP_025816775.1), Panicum miliaceum (RLM92289.1), A. thaliana (NP_680161.1), Capsicum annuum (AY71222.1), O. sativa (AB028184.1), Glycine max (EU440353.1), Phalaenopsis bellina (KY979200.1), A. thaliana (AT5G08790), T. aestivum (KT345698.1), T. aestivum (KF646593.1), A. thaliana (AT3G15170), A. thaliana (AT3G04060), Brassica napus (KP641357.1), Amborella trichopoda (XP_006827219.2), A. thaliana (AT2G43000), G. max (KRH73619). 


\subsection{Subcellular Localization and Transcriptional Activation Assay}

In order to determine the subcellular localization of CpNAC68, the plasmid 35S:CpNAC68GFP was constructed and Agrobacterium tumefaciens was used to infiltrate young leaves of Nicotiana benthamiana epidermal cells. An empty vector (35S:GFP) was used as a control. CpNAC68-GFP was only observed in punctate spherical structures reminiscent of nuclei, while the GFP signal was scattered throughout the cell periphery (Figure 2A). Since the spherical structures were only one per cell, these results strongly suggest that CpNAC68 localizes to the nucleus, which is in accordance with the function of CpNAC68 as a TF.
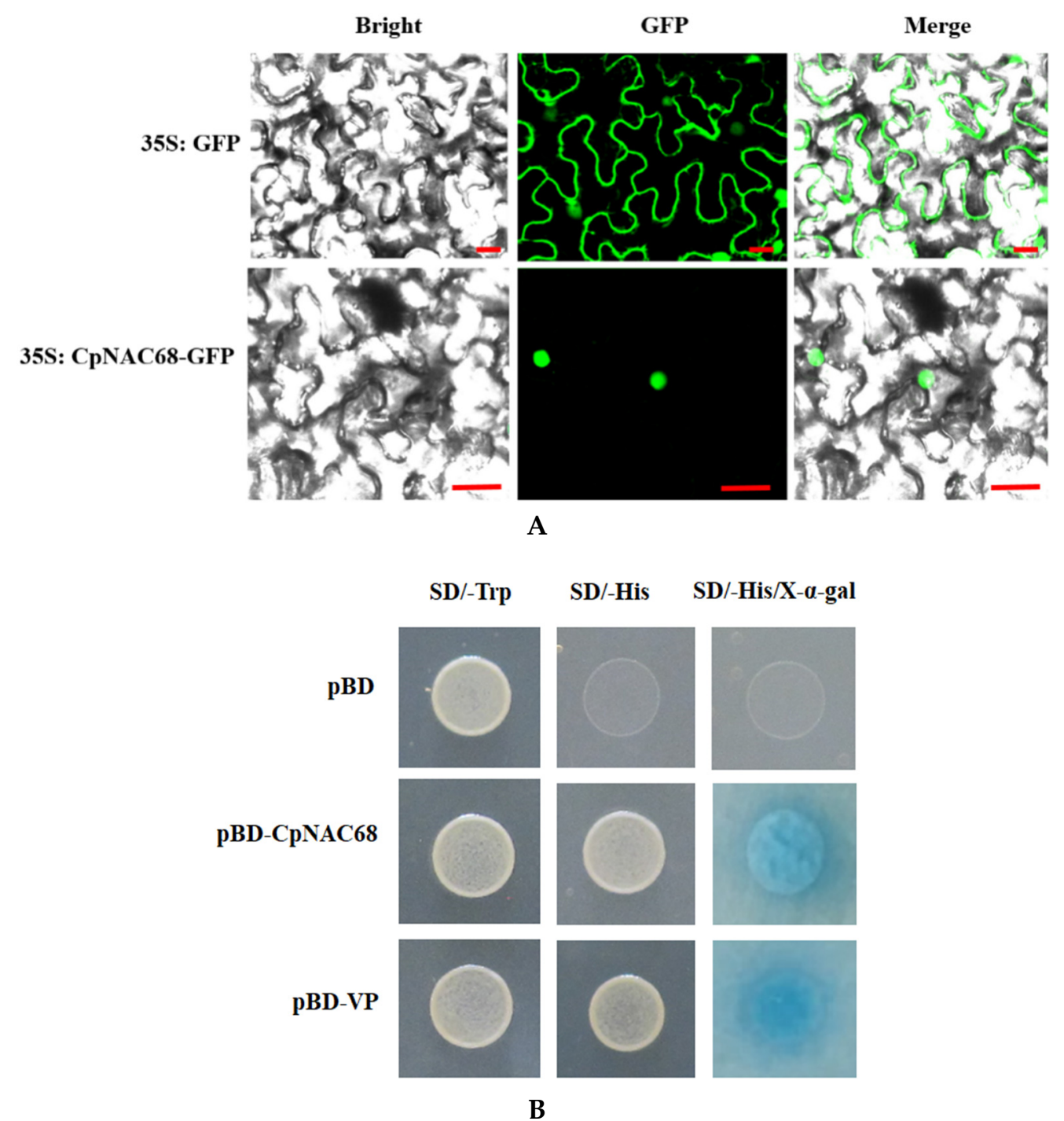

Figure 2. Subcellular localization and transcriptional activation activity of CpNAC68. (A) The control vector 35S:GFP and the recombinant vector 35S:CpNAC68-GFP were expressed in N. benthamiana leaf epidermal cells. Confocal images were captured $36 \mathrm{~h}$ after agro-infiltration and analyzed by laser scanning confocal microscope in bright, dark, and merged fields. Scale bar $=50 \mu \mathrm{m}$. (B) Y2H Gold yeast transformed with pGBKT7 (pBD) (negative control), pGBKT7-CpNAC68 (pBD-CpNAC68), and pGBKT7-VP (pBD-VP) (positive control). Growth and the $\beta$-galactosidase activity was assessed by $\mathrm{SD} / \mathrm{Trp}-\mathrm{SD} /$ His- plates and in the presence of $\mathrm{X}$ - $\alpha$-gal, respectively.

To assess whether CpNAC68 has transcriptional activation activity, the yeast expression plasmid $p G B K T 7-C p N A C 68$ was constructed by fusing the CpNAC68 CDS with a GAL4 DNA-binding domain (DBD) in the pGBKT7 vector. The empty pGBKT7 and $p G B K T 7-V P 16$ were used as the negative and positive controls, respectively. These three 
plasmids were transferred into the $\mathrm{Y} 2 \mathrm{H}$ Gold yeast strain. The results demonstrate that the three transformants grew normally on SD/Trp plates, indicating that these three plasmids were introduced successfully. Transformants were then plated on the SD/His/X- $\alpha$-gal. The yeasts carrying $p G B K T 7-C p N A C 68$ or $p G B K T 7-V P$ grew and showed $\beta$-galactosidase activity (Figure 2B). The results indicate that $\mathrm{CpNAC68}$ has activity as a transcriptional activator.

\subsection{Expression Analysis of $\mathrm{C} p N A C 68$}

qRT-PCR found that $C p N A C 68$ is preferentially expressed in mature leaves and flowers (Figure 3A). It is also highly expressed in pistils compared to other floral organs (Figure 3A). There is a gradual rise in expression level with flower development (Figure 3B). To investigate the expression pattern of $C p N A C 68$ under various abiotic stresses and hormone treatments, RNA was extracted from stress-treated young leaves and the transcript levels were measured by qRT-PCR. C $p N A C 68$ was induced by heat, salt, and cold with different temporal dynamics (Figure 3C). Expressions peaked early ( $2 \mathrm{~h}$ ) during heat, were delayed $(6 \mathrm{~h})$ during salt, and were late $(12 \mathrm{~h})$ during cold, respectively. By contrast, drought suppressed expressions. For the hormone treatments, CpNAC68 was induced by GA and JA with different temporal dynamics, and expressions were suppressed by SA treatment (Figure 3D). Therefore, $\mathrm{C} p N A C 68$ is positively and negatively regulated by specific stresses and hormones.

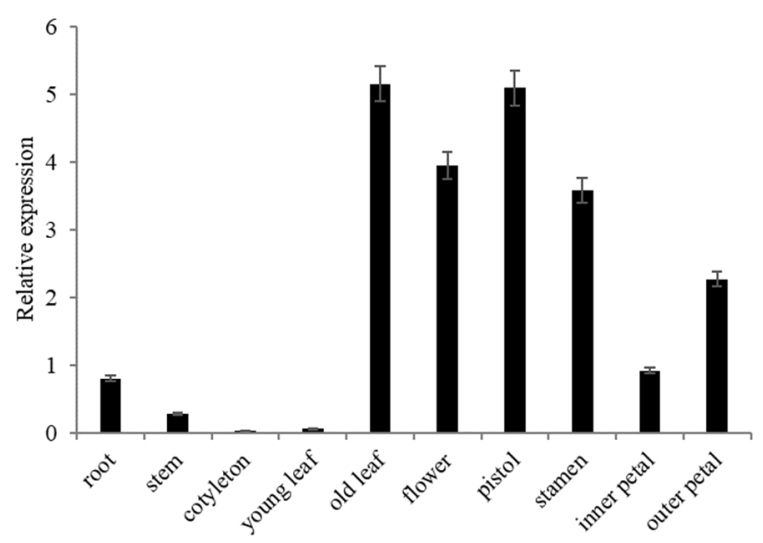

A

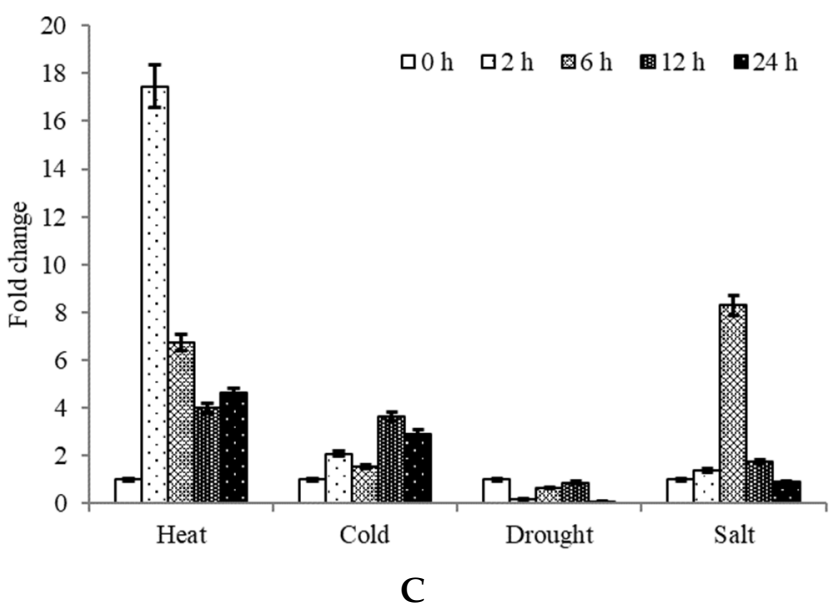

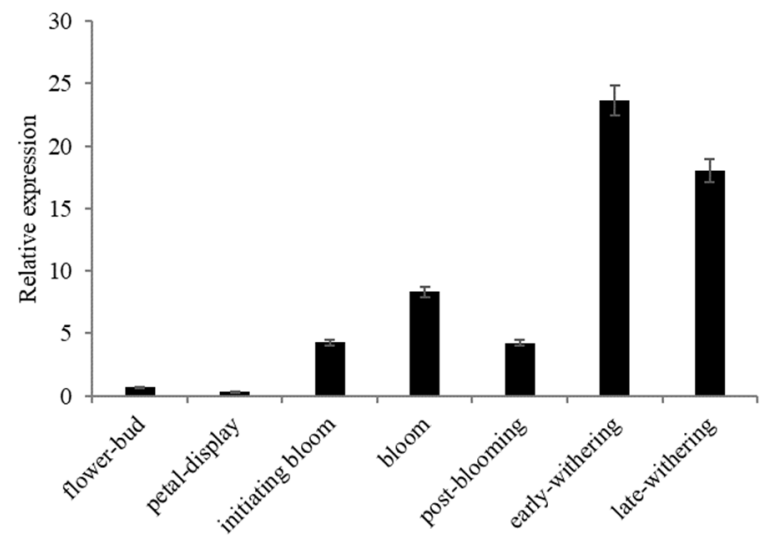

B

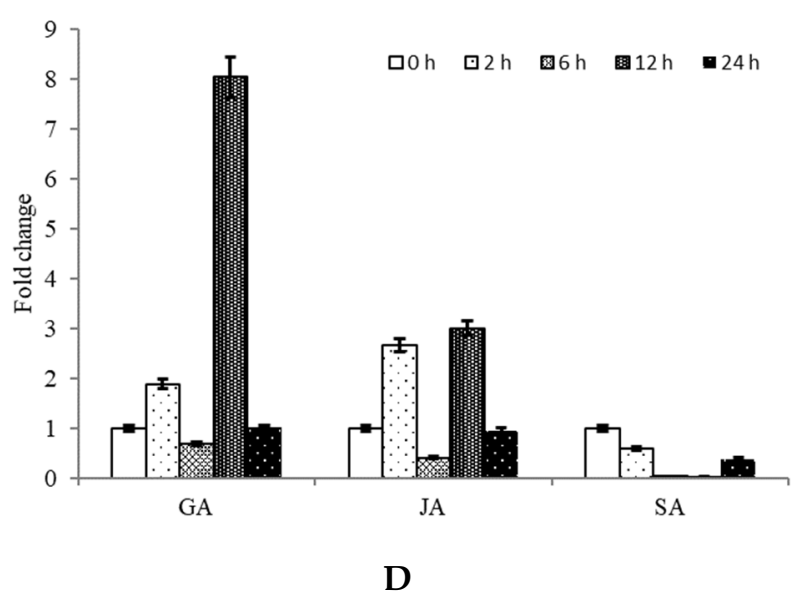

Figure 3. Analysis of $C p N A C 68$ expressions by qRT-PCR. (A) Expressions in different tissues and flora organs. (B) Flower development stages. (C) Stress treatments (heat, cold, drought, salt) at indicated time points. (D) Hormone treatments (GA, JA, SA) at indicated time points. Expression levels were normalized by CpActin. Data represent the mean of three biological repeats $\pm \mathrm{SD}$. Error bars indicate the standard deviation. 


\subsection{Abiotic Stress Tolerance of Transgenic Arabidopsis Overexpressing CpNAC68}

To further investigate the function of $C p N A C 68$, an overexpression vector pGWB551CPNAC68 was constructed and transferred into Arabidopsis. Following the selection of the T1 seeds, homozygous T2 lines were selected on hygromycin and those with the highest expression of CpNAC68 were identified by qRT-PCR (Figure 4A). We used the T3 lines that had the highest expression levels (namely, OE1, OE2, OE7) for further functional analysis. In the absence of stress treatments, no obvious changes in growth phenotype were observed (Figure 4B).

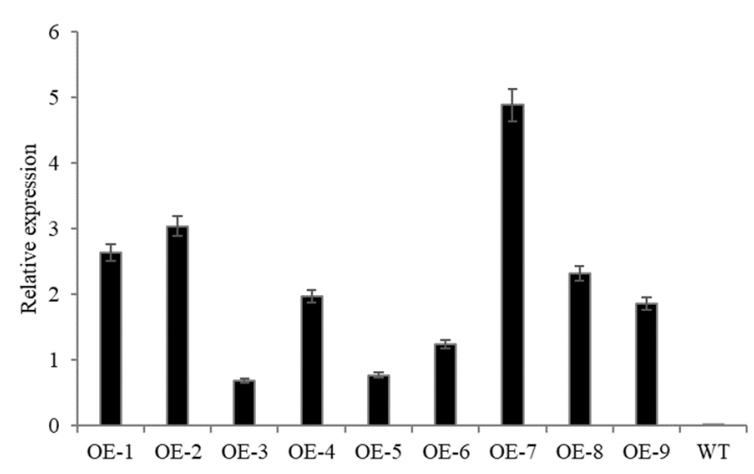

A

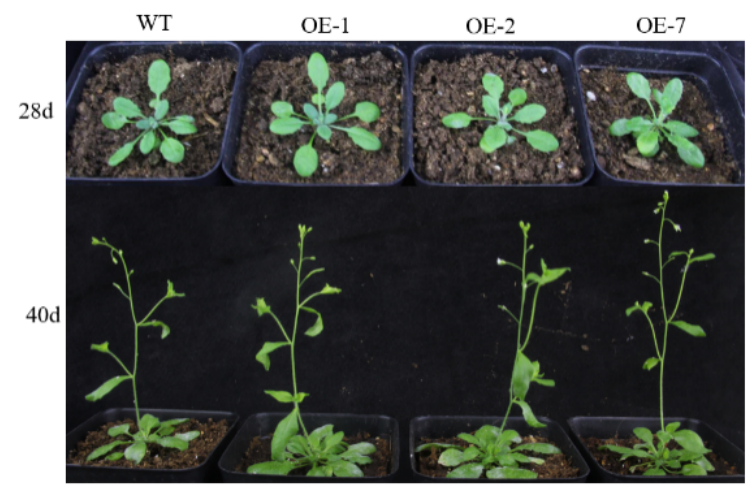

B

Figure 4. Phenotype observation of CpNAC68 in transgenic Arabidopsis. (A). qRT-PCR identification of CpNAC68 transcript levels in the leaves of nine overexpressed Arabidopsis lines and WT plants. AtActin was used as the internal reference gene; bars indicate the SE of the mean from three technical replicates and three biological replicates. (B) Phenotype observation of different transgenic lines and WT plants were at different developmental stages. Twelve individual plants for each line were used for height measurements (Figure S1). Bars correspond to standard error.

In order to ascertain the response of $C p N A C 68$ overexpression to heat stress, plants were subjected to a high temperature $\left(42^{\circ} \mathrm{C}\right)$ for 3 days. The transgenic lines clearly displayed less photobleaching, etiolation, and wilting, whereas the WT plants exhibited large areas of chlorosis and stagnation (Figure 5A). As another indicator of enhanced stress tolerance, the transgenic lines OE1, OE2, and OE7 exhibited soil plant analysis development (SPAD) values of $18.45,22.74$, and 23.96 , respectively, which were significantly higher than that of the WT plants (13.87). This indicates that CpNAC68 alleviates damage judged by the higher chlorophyll amounts in transgenic lines (Figure 5B). In support of this, the electrolyte leakage was $73.27 \%, 72.82 \%$, and $62.61 \%$, respectively, which was significantly lower than that of the wild type (80.31\%) (Figure 5C). Moreover, the molar concentration of MDA, an indicator of lipid peroxidation degree, varied from 2.61 to $3.54 \mu \mathrm{mol} / \mathrm{g} \mathrm{FW}$, which was less than half of that of the WT plants $(7.43 \mu \mathrm{mol} / \mathrm{g} \mathrm{FW})$ (Figure 5D). These results demonstrate that the overexpression of $C p N A C 68$ enhanced the heat tolerance of transgenic plants.

To explore the role of CpNAC68 as a regulator of osmotic stress in plants, both the OE lines and WT plants were irrigated with 20\% PEG. After one week of treatment, we observed that the WT plants were dehydrated and wilting. On the contrary, the transgenic Arabidopsis remained green and healthy. After 10 days of the treatment, most of the WT Arabidopsis died (Figure 6A). 


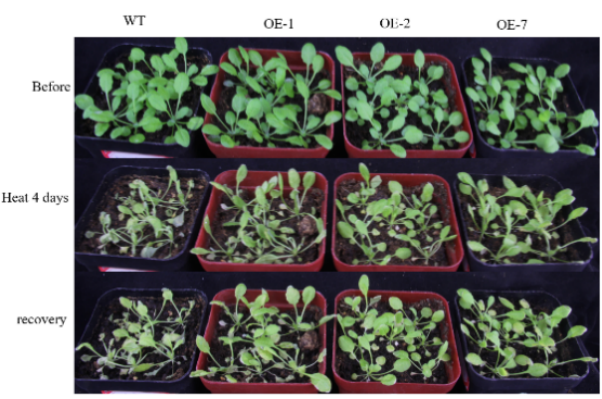

A

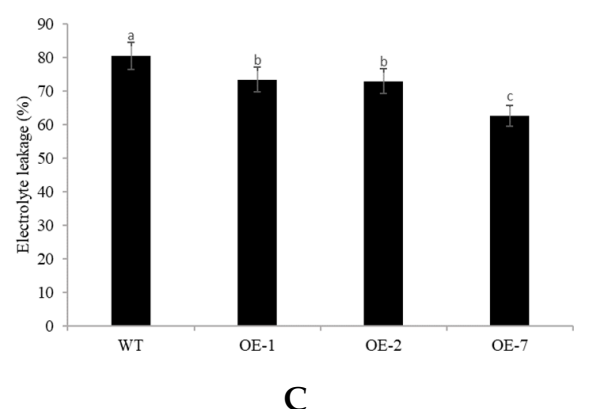

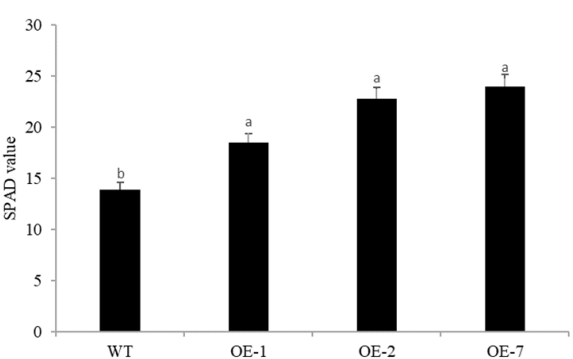

B

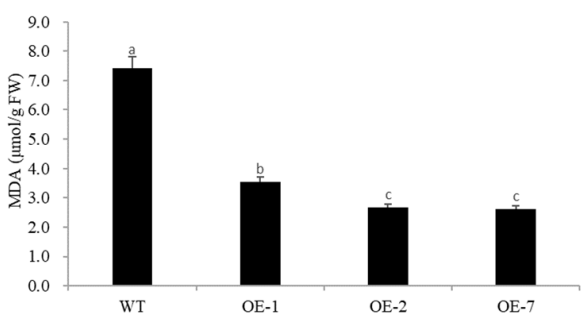

D

Figure 5. Ectopic expression of CpNAC68 confers enhanced tolerance to heat stress in transgenic Arabidopsis. (A) Performance of overexpression in OE lines and WT plants after heat stress for 4 days, followed by recovery at normal conditions for 3 days. Images were taken at the indicated time points. (B) SPAD values of OE lines and WT plants under heat treatment. (C) Electrolyte leakage of plants under heat treatment. (D) MDA content of plants under heat treatment. Values are the averages of three independent repeated trials. Data represent the mean \pm (SE). Bars correspond to the standard error. The significance test was performed by Duncan's multiple range test, which is indicated by different letters.

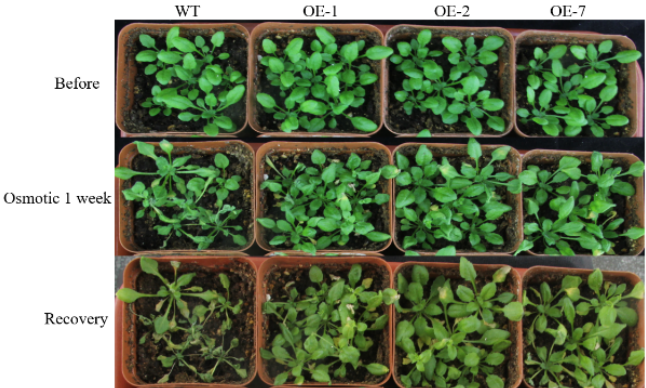

A

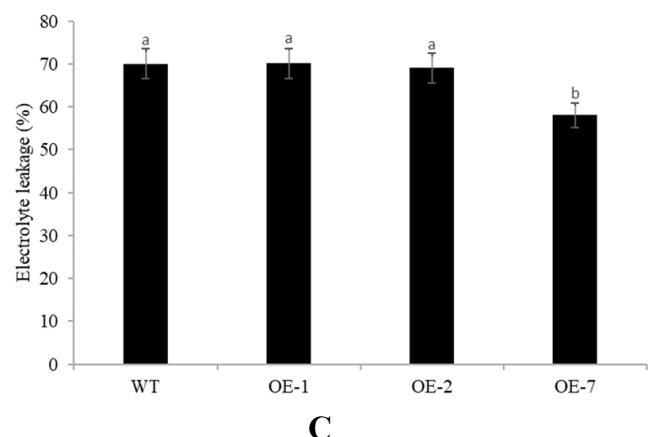

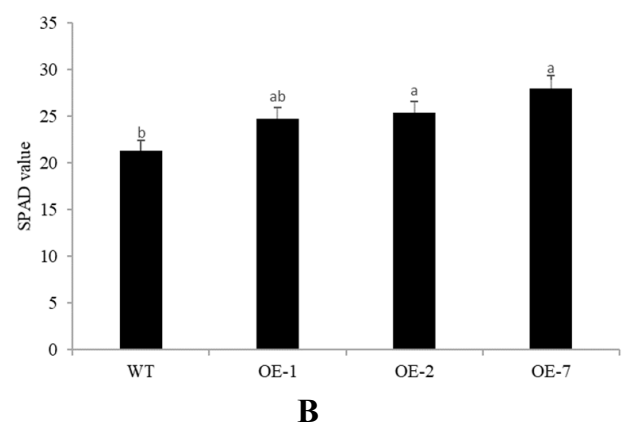

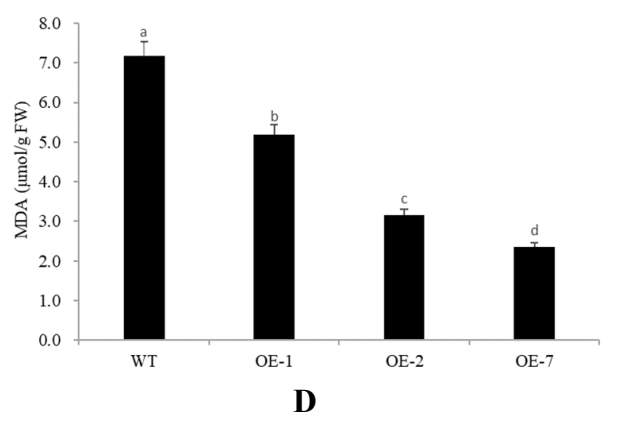

Figure 6. Ectopic expression of CpNAC68 confers improved tolerance to osmotic stress in transgenic Arabidopsis. (A) Performance of OE lines and WT plants after osmotic stress for 1 week, followed by recovery at normal conditions for 3 days. Images were taken at the indicated time points. (B) SPAD values of OE lines and WT plants under osmotic treatment. (C) Electrolyte leakage of OE lines and WT plants under osmotic treatment. (D) MDA content of OE lines and WT plants under osmotic treatment. Data represent the averages of three independent repeated trials. Values represent the mean $\pm \mathrm{SE}$. Bars correspond to the standard error. The significance test was performed by Duncan's multiple range test, which is indicated by different letters. 
The SPAD values of the CpNAC68 transgenic lines were 24.74, 25.37, and 27.99, which were significantly higher than that of the WT (21.35) (Figure 6B). No differences in electrolyte leakage were observed among the OE-1, OE-2, and WT plants, whereas the electrolyte leakage of OE-7 was significantly lower than the WT plants (58.04\% compared to $70.02 \%$, respectively) (Figure 6C). The MDA levels varied from 2.35 to $5.91 \mu \mathrm{mol} / \mathrm{g} \mathrm{FW}$, which was markedly lower than the WT plants $(7.81 \mu \mathrm{MOL} / \mathrm{g}$ FW) (Figure 6D). Thus, our data show that the overexpression of $C p N A C 68$ confers improved osmotic tolerance in the transgenic Arabidopsis.

To assess for salt stress tolerance, $500 \mathrm{~mL}$ of $\mathrm{NaCl}$ solution with a concentration of $200 \mathrm{mMOL}$ was poured into the watering trays every 5 days. After one week, the transgenic lines bloomed and produced pods normally, while the WT plants showed almost no growth even after two weeks (Figure 7A). The SPAD values of OE-1, OE-2, and OE-7 were $21.67,22.75$, and 24.44 , respectively, which were significantly higher than that of the WT plants (18.49) (Figure 7B). The electrolyte leakage was $73.26 \%$ for OE- $1,70.68 \%$ for OE-2, and $70.21 \%$ for OE-7, which was significantly lower than that of the WT plants $(75.05 \%$ ) (Figure 7C). The MDA levels were about $2.6 \mu \mathrm{MOL} / \mathrm{g}$ FW, which was almost half of that of the WT (4.39 $\mu \mathrm{MOL} / \mathrm{g} \mathrm{FW)} \mathrm{(Figure} \mathrm{7D).} \mathrm{In} \mathrm{summary,} \mathrm{under} \mathrm{high} \mathrm{salt} \mathrm{stress,} \mathrm{the}$ membrane system of transgenic $C p N A C 68$ Arabidopsis is more resistant to damage than the WT.

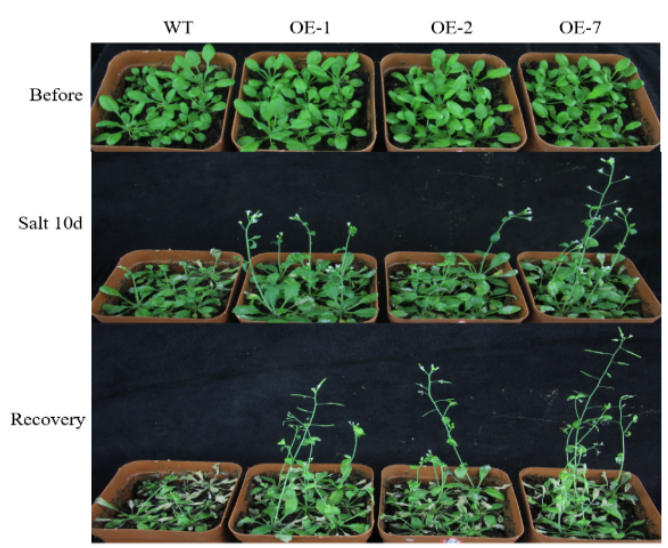

A

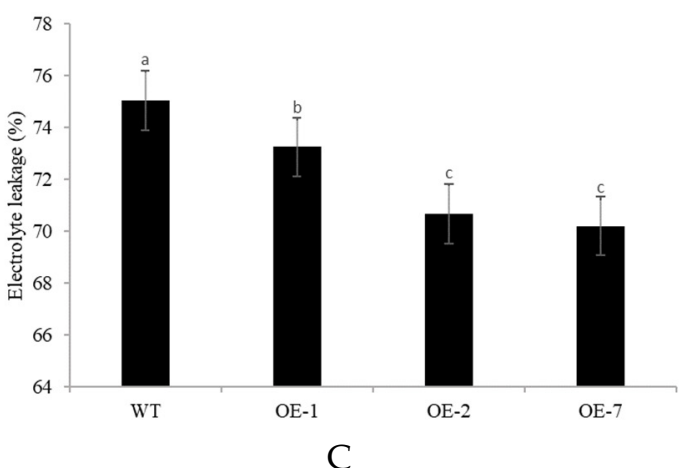

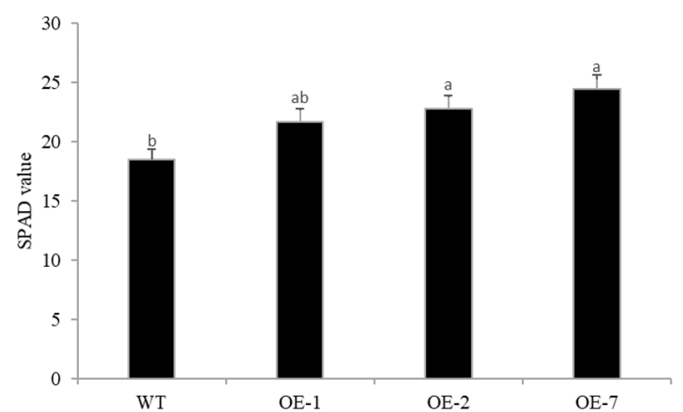

B

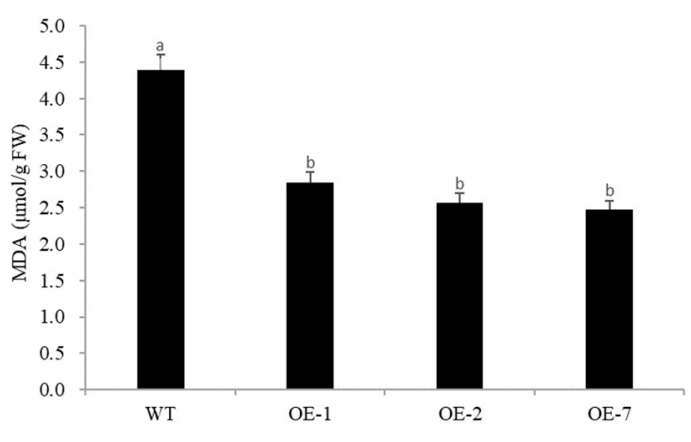

$\mathrm{D}$

Figure 7. Overexpression of CpNAC68 confers enhanced tolerance to salt stress in transgenic Arabidopsis. (A) Performance of OE lines and WT plants after salt stress for 10 days, followed by recovery at normal conditions for 4 days. Images were taken at the indicated time points. (B) SPAD value of OE lines and WT plants under salt treatment. (C) Electrolyte leakage of OE lines and WT plants under salt treatment. (D) MDA content of OE lines and WT plants under salt treatment. Values represent the averages of three independent repeated trials. Data represent the mean \pm SE. Bars correspond to the standard error. The significance test was performed by Duncan's multiple range test, which is indicated by different letters.

Finally, we assessed cold stress tolerance. After $6 \mathrm{~h}$ of low temperature $\left(-4{ }^{\circ} \mathrm{C}\right)$ treatment, the transgenic lines exhibited impressively higher survival rates at $71.42 \%$, $85.71 \%$, and $92.85 \%$, compared to the WT (28.57\%) (Figure $8 \mathrm{~A})$. After being returned to a 
normal temperature for 3 days, most of the transgenic plants resumed growth, while the WT plants remained wilting and eventually died (Figure 8B). Thus, CpNAC68 participates in cold stress tolerance when overexpressed in Arabidopsis.

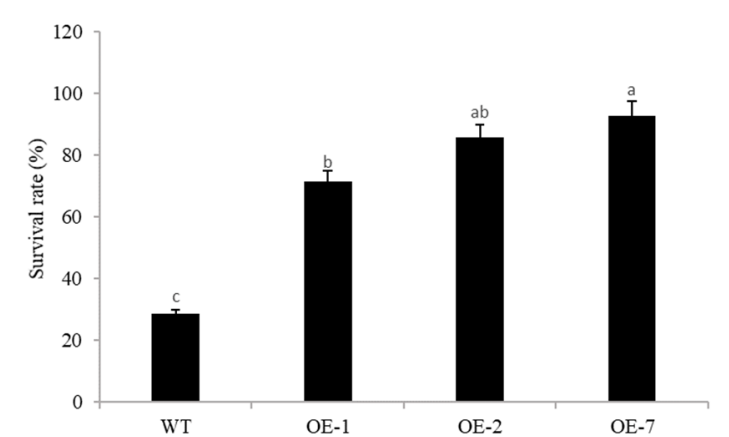

A

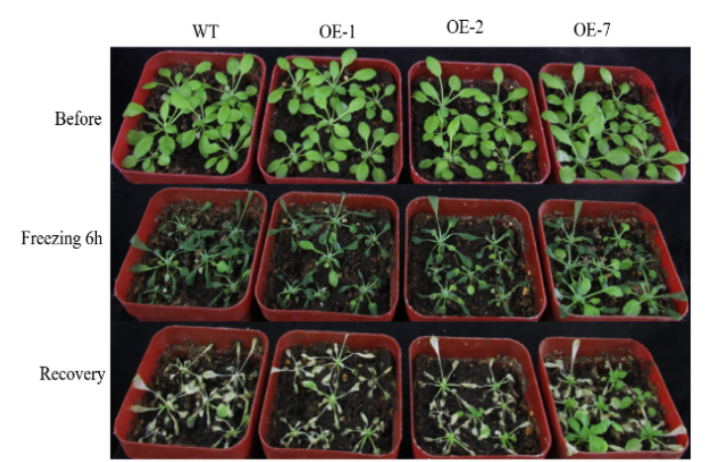

B

Figure 8. Improvement of freezing tolerance using C $p N A C 68-\mathrm{OE}$ in Arabidopsis. (A) Survival rates of $C p N A C 68$ OE and WT plants under freezing stress. Values represent the mean $\pm \mathrm{SE}(n=3)$. Bars correspond to the standard error. The significance test was performed by Duncan's multiple range test, which is indicated by different letters. (B) CpNAC68 OE and WT seedling performance under freezing stress. One-month-old plants were subjected to $-4{ }^{\circ} \mathrm{C}$ for $6 \mathrm{~h}$, then transferred back to normal conditions to promote recovery for 3 days. Pictures were taken after each time point.

\section{Discussion}

Over the last decade, genes of the NAC family have been characterized mainly by model plant species. Notable studies have shown the diversity of the NAC family and the complexity of their functions, including complex miRNA regulatory mechanisms at the level of transcription [52], and NAC protein phosphorylation and ubiquitination [53]. In this study, we isolated the CpNAC68 gene from wintersweet. Protein sequence analysis revealed that the N-terminal half of CpNAC68 possesses a conserved domain of the NAC gene family, specifically NAM subfamily-like domain. Bioinformatics analysis indicated that the CpNAC68 protein is hydrophilic and contains no obvious signal peptide or transmembrane domain, like most other NACs [51]. Clustering CpNAC68 with NAC proteins demonstrated the closest amino acid similarity to the drought and salt tolerance protein MusaNAC68 from M. Acuminate, and multiple abiotic tolerance proteins TaNAC47 and TaNAC67 from T. aestivum. Since CpNAC68 expression was found to be upregulated during wintersweet flowering, which is stimulated by cold temperatures, and the protein was similar to MusaNAC68, TaNAC47, and TaNAC67, we hypothesized that $C p N A C 68$ has a role in regulating abiotic stress tolerance.

Localization of the CpNAC68-GFP fusion protein in N. benthamiana cells found fluorescent signals only in the nucleus. This is similar to most characterized NACs, such as SNAC3 [54], AaNAC1 [55], GhNAC2 [56], and CaNAC064 [57]. However, some involved in regulating pathogen stress responses, such as GFP-GmNAC42-1 from soybean, have also been detected in the cytosol [58]. Consistent with a role as a TF, CpNAC68 had transcriptional activation activity when expressed in yeast. Previous studies have reported that a large number of NAC TFs have transcriptional activation functions, such as ONAC063 [59], OsNAC111 [60], CaNAC064 [57], ChNAC1 [61], and GmNAC42-1 [58].

CpNAC68 was expressed in all of the wintersweet tissues tested, with the highest expression in old leaves and flowers (Figure 3A). In addition, CpNAC68 had different expression levels at different flower development stages, with the highest expressions observed during the bloom stage (Figure 3B). Thus, CpNAC68 may regulate cellular or physiological factors to provide stress tolerance during wintersweet flower senescence. C pNAC68 was upregulated by cold, heat, and salt stresses (Figure 3C). While CpNAC68 demonstrated some considerable fluctuations in gene expression in response to GA and JA (Figure 3D), similar to LrNAC35 [62] and OoNAC72 [63], some consistent changes 
in gene expression were observed in response to other hormones and stress treatments. However, CpNAC68 was downregulated by drought and SA treatment (Figure 3C,D), which is in contrast with MusaNAC68 [64]. Other NACs, such as SNAC3 were induced by drought, salt, heat, oxidative stress, and ABA, but suppressed by cold, submergence, and wounding [54]. GmNAC081 and GmNAC030 were implicated in triggering leaf senescence, and were induced by drought, salt, and cold, as well as ABA, SA, MeJA [65]. Thus, we speculated that CpNAC68 may be involved in regulating heat, cold, salt, and other stresses.

To validate our hypothesis and better understand the function of CpNAC68, we overexpressed its largest ORF in Arabidopsis. We found no obvious phenotypic differences between the transgenic lines and the WT plants. This is notable since most ectopically overexpressed NAC genes will not adversely affect the development of transgenic plants $[56,66]$. They can also cause curly and shrunken leaves and dwarfing [17]. Under the heat, osmotic, and salt stresses, the survival rate and chlorophyll SPAD values of transgenic C $p N A C 68$ Arabidopsis were significantly higher than that of the WT plants, while the relative electrolyte leakage and the MDA content were significantly lower than that of the WT plants. Collectively, our results indicate that the overexpression of C $p N A C 68$ confers enhanced tolerance to multiple stresses and thus, has a positive regulatory role in stress response processes in Arabidopsis.

Currently, there has been one other NAC68 protein that was functionally characterized. MusaNAC68 conferred enhanced tolerance to drought and high salt stress when expressed in transgenic $M$. acuminata [64], and it reduced xylem secondary wall thickness [67]. Differently than MusaNAC68, CpNAC68 was downregulated by drought and confers tolerance to other stresses (i.e., cold, heat, osmotic, and salt) when ectopically expressed in Arabidopsis. Some other NACs have been shown to confer tolerance to multiple stresses. Transgenic $S N A C 3$ rice grew better than the WT plants under high temperatures, drought, and oxidative stress [54]. Overexpressing ONAC063 in Arabidopsis could confer improved tolerance to salt, heat, and osmotic stress [59]. Furthermore, with involvement in the ABA-dependent signaling pathway, SINAC1 rendered the enhanced resistance of transgenic plants under drought, salt, and cold stress [68], and TaNAC47 [66] and TaNAC67 [69] simultaneously enhanced these three abiotic stress tolerances. However, some NAC genes reduce stress tolerance. For example, the ectopic overexpression of BoNAC019 in Arabidopsis reduced survival rate, proline, and ABA content, under drought stress. Similarly, LpNAC13 reduced drought tolerance in transgenic tobacco, but improved salt tolerance, despite being induced by drought, salt, cold, and ABA treatments [70]. Overall, various NAC genes play multiple complex roles in regulating abiotic stress tolerance in different species. Future work needs to concentrate on the mechanism of action of CPNAC68 on downstream genes and metabolites in wintersweet.

\section{Materials and Methods}

\subsection{Plant Materials and Growth Conditions}

For gene expression profiling, seeds of wintersweet were cultivated in a greenhouse at Southwest University, Chongqing, China. Tissues, including the root, stem, cotyledon, leaves, flowers, and floral organs in full bloom (stamen, pistil, outer petal, middle petal, and inner petal), were dissected and flash-frozen in liquid nitrogen. According to the classification of wintersweet floral stages [44], the flowers were collected at the lower-bud, petal-display, initiating bloom, bloom, post-blooming, early-withering, and late-withering stages, respectively.

N. Benthamiana was used for the subcellular localization assay. N. benthamiana seedlings were grown under a $16 \mathrm{~h}$ light (2000 lux) and $8 \mathrm{~h}$ dark photoperiod with a constant temperature $\left(22 \pm 1^{\circ} \mathrm{C}\right)$ and relative humidity $(75 \% \mathrm{RH})$.

For plant transformation, seeds of Arabidopsis ecotype Columbia-0 (Col-0) were vernalized under $4{ }^{\circ} \mathrm{C}$ for three days, then sterilized in $2 \%$ sodium hypochlorite solution, followed by five rinses with sterile water. Subsequently, the sterilized seeds were spread on MS plates. The MS plates containing the Arabidopsis seeds were stored in a plant incubator 
with the same photoperiod as $N$. benthamiana $\left(22 \pm 1{ }^{\circ} \mathrm{C}, 75 \% \mathrm{RH}\right)$. After two weeks, the seedlings were transplanted into a 1:1 mixture of peat and vermiculite and grown under the same conditions as above.

\subsection{Cloning and Sequence Analysis}

Total RNA was isolated from the plant tissues (lyophilized powder) using the Plant RNA Purification Kit (Tiangen Biotech, Beijing, China) following the manufacturer's instructions. For quality and quantity control, the RNA extracts were visualized by $1 \%$ agarose gel electrophoresis, then quantified with a Nano-Drop ND-1000 spectrophotometer (Thermo Fisher Scientific, Wilmington, MA, USA) at optical densities of 260 and $280 \mathrm{nM}$.

The first-strand cDNA was synthesized from total RNA using a PrimeScript RT Reagent Kit with gDNA Eraser (TaKaRa, Otsu, Japan). CpNAC68 was amplified from cDNA templates (mixed with leaves and flower tissues) accompanied with the specific primers CpNAC68-F/R (Table S1). Subsequently, the products above were isolated and confirmed by sequencing, as described by Huang et al. [47]. The sequence identity of CpNAC68 was determined by a homology search in the National Center for Biotechnology Information (NCBI) database by the Protein-BLAST program (http:/ / www.ncbi.nlm.nih.gov/, accessed on 3 May 2019). The amino acid sequences of various NAC proteins from other species for multiple sequence alignment and cluster tree construction were retrieved from the NCBI database. Multiple sequence alignment was performed using the online tool Multalin (http:/ / multalin.toulouse.inra.fr/multalin/, accessed on 5 July 2020). The cluster analysis tree was generated by MEGA 7.0 with the neighbor-joining (NJ) method [71].

\section{3. $C p N A C 68$ Expression Analyses}

The expression profiles of $C p N A C 68$ of different tissues, organs, and floral stages, as well as stress and chemical treatments, were determined by qRT-PCR analyses with the primers $C p N A C 68-\mathrm{qF} / \mathrm{qR}$ (Table S1). qRT-PCR was performed as described by Liu et al. [44]. CpActin and AtActin were used as reference genes to normalize the data. The relative gene expression levels were calculated by the $\mathrm{Ct}$ method $\left(2^{-\Delta \Delta C t}\right)$ [72]. Each reaction comprised three biological and technical replicates [73].

\subsection{Subcellular Localization and Transactivation Activity Assay of CpNAC68}

Specific primers CpNAC68-slF/slR (Table S1), containing KpnI and XbaI restriction sites, were designed to clone $C p N A C 68$ without a termination codon (TGA) into pCAMBIA1300. The $p C A M B I A 1300:: C p N A C 68-G F P$ and the empty vector were separately infiltrated into $N$. benthamiana epidermal cells mediated by A. tumefaciens strain GV3101. The GFP fluorescence was observed by confocal laser microscopy (Olympus, Japan).

pGBKT7 was digested with NdeI and NotI; the related primers are listed in Table S1. Then, the recombinant plasmid was transformed into the $\mathrm{Y} 2 \mathrm{H}$ Gold yeast strain. pGBKT7VP and pGBKT7 were utilized as the positive and negative controls, respectively. We used $\mathrm{SD} / \mathrm{Tr} p$ plates to select positive transformants. For the transactivation assay, $\mathrm{SD} / \mathrm{His} / \mathrm{X}-\alpha-$ gal plates were used to evaluate the transcriptional activity.

\subsection{Overexpressed Plasmid Construction and Arabidopsis Transformation}

CpNAC68 was fused in-frame into the pGWB551 vector by the Gateway recombination reactions with specified primer $C p N A C 68-\mathrm{gF} / \mathrm{gR}$, as shown in Table S1. After being confirmed by sequencing, the $p$ GWB551-C $p N A C 68$ plasmid was transformed into A. tumefaciens to further explore the function of CpNAC68. Arabidopsis ecotype Col-0 was used for the genetic transformation, which was carried out by the floral dip method [74]. T0 seeds were sowed in MS media containing $25 \mathrm{mg} / \mathrm{L}$ hygromycin for transgene selection. The overexpression status of $C p N A C 68$ in the T3 homozygous line was confirmed by qRT-PCR under the normalization of AtActin with the primers listed in Table S1. Then, the three T3 homozygous lines with relatively higher expression levels were used for the phenotypic analyses in the stress tolerance experiments. 


\subsection{Stress Treatments and Phenotype Observation}

In order to understand the gene expression patterns under different abiotic stresses and hormone treatments, three-month-old wintersweet seedlings were used. Heat treatment was conducted by transferring the seedlings to a growth chamber at $42{ }^{\circ} \mathrm{C}$ with a $16 \mathrm{~h}$ light $/ 8 \mathrm{~h}$ dark cycle (2000 lux). Cold treatment was conducted by transferring the seedlings to a growth chamber at $4{ }^{\circ} \mathrm{C}$ with a $16 \mathrm{~h}$ light $/ 8 \mathrm{~h}$ dark cycle (2000 lux). For the salt and drought stress treatments, the seedlings were grown in soil irrigated with $150 \mathrm{mM} \mathrm{NaCl}$ or $20 \%$ PEG 6000 (polyethylene glycol 6000), respectively. For exogenous hormone treatments, the wintersweet seedlings were treated with $10 \mu \mathrm{M} \mathrm{GA}, 100 \mu \mathrm{M} \mathrm{JA}$, and $2 \mathrm{mM} \mathrm{SA}$ for $24 \mathrm{~h}$, respectively. Two leaves of one individual wintersweet seedling were collected as one replicate at $0,2,6,12$, and $24 \mathrm{~h}$ after treatment, and frozen in liquid nitrogen. There were three biological replicates for each treatment.

To evaluate the drought, salt, heat, and freezing tolerance of the transgenic CpNAC68 Arabidopsis, 4-week-old T3 plants were used. For heat treatment, the seedlings were exposed to $42{ }^{\circ} \mathrm{C}$ for 6 days, then returned to the normal conditions in a growth chamber. For freezing treatment, the seedlings were exposed to $-4{ }^{\circ} \mathrm{C}$ for 4 hours, and subsequently returned to the normal growth conditions. For osmotic treatment, the seedlings were well irrigated for 4 weeks, then watered with 20\% PEG 6000. For salt stress treatment, the seedlings were watered with a concentration of $200 \mathrm{mM} \mathrm{NaCl}$ solution every 5 days. The controlled plants were grown at $25^{\circ} \mathrm{C}$ and were mock-treated with water. For each tested tissue, three biological replicates were collected by harvesting samples from three different plants.

The physiological parameters of stress tolerance were measured by the survival rate, the chlorophyll SPAD value, electrolyte leakage, and the MDA content. For freezing stress, the survival rate was scored one week after treatment. The chlorophyll SPAD values were determined according to Mao et al. [69]. Electrolyte leakage was measured as described [75]. The MDA content was measured using the thiobarbituric acid-based (TBA) method, following Robert L. Heath [76].

\subsection{Statistical Analysis}

SPSS (IBM SPSS Statistics 22) software was used to analyze the differences of paired data with Duncan's multiple range tests. The values of $p<0.05$ and $p<0.01$ were indicative of statistical significance, which were recognized as statistically significant and extremely significant, respectively. All trials were independently repeated at least three times.

\section{Conclusions}

We cloned the NAM-subfamily NAC TF gene CpNAC68 from wintersweet and provided evidence that it is a nuclear-localized activator of transcription. CpNAC68 expressions were induced by multiple abiotic stresses (drought, salt, cold, and heat), as well as hormone treatments (SA, JA, and GA). Overexpressing C $p N A C 68$ ectopically in Arabidopsis enhanced tolerance to cold, heat, osmotic, and salt stresses. Thus, $\mathrm{C} p N A C 68$ has a role in positively regulating stress tolerance.

Supplementary Materials: The following are available online at https:/ /www.mdpi.com/article/10 .3390/plants10071403/s1. Figure S1: Plant height of 40-day-old WT and transgenic plants; Table S1: List of primers used in this study.

Author Contributions: S.S. conceived and designed the experiments. J.L., D.L. and X.W. performed the experiments. J.L., D.L. and X.W. collected and analyzed the data. N.K., J.L. and M.L. wrote and S.A. proofread the paper. All authors have read and agreed to the published version of the manuscript.

Funding: This research was funded by the National Natural Science Foundation of China (No.31971711), Natural Science Foundation Project of Chongqing (No.cstc2020jcyj-msxmX0754).

Institutional Review Board Statement: Not applicable. 
Informed Consent Statement: Not applicable.

Data Availability Statement: Not Applicable.

Acknowledgments: We are thankful to Yingnan Tian from the College of Horticulture and Landscape, Yunan Agricultural University, and Yu Wang from the College of Life Science, Tarim University for their suggestions and support. We are also thankful to the editor of the journal and anonymous reviewers for their time and comments in improving/publishing this article.

Conflicts of Interest: The authors declare no conflict of interest.

\section{References}

1. Toth, Z.; Kiss, E.; Kovacs, L. NAC transcription factors as key regulators in stress responses. Acta Hortic. 2014, 1082, 293-298. [CrossRef]

2. Franco, A.A.; Odom, R.S.; Rando, T.A. Regulation of antioxidant enzyme gene expression in response to oxidative stress and during differentiation of mouse skeletal muscle. Free Radic. Biol. Med. 1999, 27, 1122-1132. [CrossRef]

3. Tucker, M.R.; Lou, H.; Aubert, M.K.; Wilkinson, L.; Little, A.; Houston, K.; Pinto, S.C.; Shirley, N.J. Exploring the Role of Cell Wall-Related Genes and Polysaccharides during Plant Development. Plants 2018, 7, 42. [CrossRef]

4. Erpen, L.; Devi, H.S.; Grosser, J.W.; Dutt, M. Potential use of the DREB/ERF, MYB, NAC and WRKY transcription factors to improve abiotic and biotic stress in transgenic plants. Plant Cell Tissue Organ. Cult. (PCTOC) 2018, 132, 1-25. [CrossRef]

5. Riechmann, J.L.; Heard, J.; Martin, G.; Reuber, L.; Jiang, C.-Z.; Keddie, J.; Adam, L.; Pineda, O.; Ratcliffe, O.J.; Samaha, R.R.; et al. Arabidopsis Transcription Factors: Genome-Wide Comparative Analysis Among Eukaryotes. Science 2000, 290, 2105-2110. [CrossRef] [PubMed]

6. Wang, Z.; Dane, F. NAC (NAM/ATAF/CUC) transcription factors in different stresses and their signaling pathway. Acta Physiol. Plant. 2013, 35, 1397-1408. [CrossRef]

7. Ernst, H.A.; Olsen, A.N.; Skriver, K.; Larsen, S.; Leggio, L.L. Structure of the conserved domain of ANAC, a member of the NAC family of transcription factors. EMBO Rep. 2004, 5, 297-303. [CrossRef] [PubMed]

8. Olsen, A.N.; Ernst, H.A.; Leggio, L.L.; Skriver, K. NAC transcription factors: Structurally distinct, functionally diverse. Trends Plant Sci. 2005, 10, 79-87. [CrossRef] [PubMed]

9. Guo, Y.; Gan, S. AtNAP, a NAC family transcription factor, has an important role in leaf senescence. Plant J. 2006, 46, 601-612. [CrossRef] [PubMed]

10. Liang, C.; Wang, Y.; Zhu, Y.; Tang, J.; Hu, B.; Liu, L.; Ou, S.; Wu, H.; Sun, X.; Chu, J.; et al. OsNAP connects abscisic acid and leaf senescence by fine-tuning abscisic acid biosynthesis and directly targeting senescence-associated genes in rice. Proc. Natl. Acad. Sci. USA 2014, 111, 10013-10018. [CrossRef]

11. Liu, Y.-Z.; Baig, M.N.R.; Fan, R.; Ye, J.; Cao, Y.-C.; Deng, X.-X. Identification and Expression Pattern of a Novel NAM, ATAF, and CUC-Like Gene from Citrus sinensis Osbeck. Plant Mol. Biol. Rep. 2009, 27, 292-297. [CrossRef]

12. Fan, J.-P.; Zhao, R. Cloning and Expression Pattern Analysis of the ApNAP Gene in Asarina procumbens. Plant Sci. J. 2014, 32, 251-258. [CrossRef]

13. Chen, X.; Wang, Y.; Lv, B.; Li, J.; Luo, L.; Lu, S.; Zhang, X.; Ma, H.; Ming, F. The NAC Family Transcription Factor OsNAP Confers Abiotic Stress Response Through the ABA Pathway. Plant Cell Physiol. 2014, 55, 604-619. [CrossRef] [PubMed]

14. Souer, E.; van Houwelingen, A.; Kloos, D.; Mol, J.; Koes, R. The No Apical Meristem Gene of Petunia Is Required for Pattern Formation in Embryos and Flowers and Is Expressed at Meristem and Primordia Boundaries. Cell 1996, 85, 159-170. [CrossRef]

15. Duval, M.; Hsieh, T.-F.; Kim, S.Y.; Thomas, T.L. Molecular characterization of AtNAM: A member of the Arabidopsis NAC domain superfamily. Plant Mol. Biol. 2002, 50, 237-248. [CrossRef]

16. Aida, M.; Ishida, T.; Fukaki, H.; Fujisawa, H.; Tasaka, M. Genes involved in organ separation in Arabidopsis: An analysis of the cup-shaped cotyledon mutant. Plant Cell 1997, 9, 841-857. [CrossRef]

17. Zhao, Y.; Sun, J.; Xu, P.; Zhang, R.; Li, L. Intron-Mediated Alternative Splicing of WOOD-ASSOCIATED NAC TRANSCRIPTION FACTOR1B Regulates Cell Wall Thickening during Fiber Development in Populus Species. Plant Physiol. 2014, 164, 765-776. [CrossRef]

18. Hu, R.; Qi, G.; Kong, Y.; Kong, D.; Gao, Q.; Zhou, G. Comprehensive Analysis of NAC Domain Transcription Factor Gene Family in Populus trichocarpa. BMC Plant Biol. 2010, 10, 145. [CrossRef]

19. Ohashi-Ito, K.; Oda, Y.; Fukuda, H. Arabidopsis VASCULAR-RELATED NAC-DOMAIN6 Directly Regulates the Genes That Govern Programmed Cell Death and Secondary Wall Formation during Xylem Differentiation. Plant Cell 2010, 22, $3461-3473$. [CrossRef]

20. Yamaguchi, M.; Kubo, M.; Fukuda, H.; Demura, T. VASCULAR-RELATED NAC-DOMAIN7 is involved in the differentiation of all types of xylem vessels in Arabidopsis roots and shoots. Plant J. 2008, 55, 652-664. [CrossRef] [PubMed]

21. Christianson, J.A.; Dennis, E.S.; Llewellyn, D.; Wilson, I. ATAF NAC transcription factors: Regulators of plant stress signaling. Plant Signal. Behav. 2010, 5, 428-432. [CrossRef] [PubMed] 
22. Zhan, P.-L.; Ke, S.-W.; Zhang, P.-Y.; Zhou, C.-C.; Fu, B.-L.; Zhang, X.-Q.; Zhong, T.-X.; Chen, S.; Xie, X.-M. Overexpression of two cold-responsive ATAF-like NAC transcription factors from fine-stem stylo (Stylosanthes guianensis var. intermedia) enhances cold tolerance in tobacco plants. Plant Cell Tissue Organ. Cult. (PCTOC) 2018, 135, 545-558. [CrossRef]

23. Gong, L.; Zhang, H.; Liu, X.; Gan, X.; Nie, F.; Yang, W.; Zhang, L.; Chen, Y.; Song, Y.; Zhang, H. Ectopic expression of HaNAC1, an ATAF transcription factor from Haloxylon ammodendron, improves growth and drought tolerance in transgenic Arabidopsis. Plant Physiol. Biochem. 2020, 151, 535-544. [CrossRef]

24. Jia, D.; Gong, X.; Li, M.; Li, C.; Sun, T.; Ma, F. Overexpression of a Novel Apple NAC Transcription Factor Gene, MdNAC1, Confers the Dwarf Phenotype in Transgenic Apple (Malus domestica). Genes 2018, 9, 229. [CrossRef] [PubMed]

25. Laubscher, M.; Brown, K.; Tonfack, L.B.; Myburg, A.A.; Mizrachi, E.; Hussey, S.G. Temporal analysis of Arabidopsis genes activated by Eucalyptus grandis NAC transcription factors associated with xylem fibre and vessel development. Sci. Rep. 2018, 8, 1-14. [CrossRef]

26. Zhang, L.; Yao, L.; Zhang, N.; Yang, J.; Zhu, X.; Tang, X.; Calderón-Urrea, A.; Si, H. Lateral Root Development in Potato Is Mediated by Stu-mi164 Regulation of NAC Transcription Factor. Front. Plant Sci. 2018, 9, 383. [CrossRef]

27. Jin, R.; Zhu, Q.-G.; Shen, X.-Y.; Wang, M.-M.; Jamil, W.; Grierson, D.; Yin, X.-R.; Chen, K.-S. DkNAC7, a novel high-CO 2 /hypoxiainduced NAC transcription factor, regulates persimmon fruit de-astringency. PLoS ONE 2018, 13, e0194326. [CrossRef]

28. Moyano, E.; Martínez-Rivas, F.J.; Blanco-Portales, R.; Molina-Hidalgo, F.J.; Ric-Varas, P.; Matas-Arroyo, A.J.; Caballero, J.L.; Muñoz-Blanco, J.; Rodríguez-Franco, A. Genome-wide analysis of the NAC transcription factor family and their expression during the development and ripening of the Fragaria $\times$ ananassa fruits. PLoS ONE 2018, 13, e0196953. [CrossRef]

29. Nuruzzaman, M.; Sharoni, A.M.; Kikuchi, S. Roles of NAC transcription factors in the regulation of biotic and abiotic stress responses in plants. Front. Microbiol. 2013, 4, 248. [CrossRef] [PubMed]

30. Eshao, H.-B.; Ewang, H.; Etang, X. NAC transcription factors in plant multiple abiotic stress responses: Progress and prospects. Front. Plant Sci. 2015, 6, 902. [CrossRef]

31. He, X.; Zhu, L.; Xu, L.; Guo, W.; Zhang, X. GhATAF1, a NAC transcription factor, confers abiotic and biotic stress responses by regulating phytohormonal signaling networks. Plant Cell Rep. 2016, 35, 2167-2179. [CrossRef]

32. Nagahage, I.S.P.; Sakamoto, S.; Nagano, M.; Ishikawa, T.; Mitsuda, N.; Kawai-Yamada, M.; Yamaguchi, M. An Arabidopsis NAC domain transcription factor, ATAF2, promotes age-dependent and dark-induced leaf senescence. Physiol. Plant. 2020, 170, 299-308. [CrossRef]

33. Yang, Z.; Wang, C.; Qiu, K.; Chen, H.; Li, Z.; Li, X.; Song, J.; Wang, X.; Gao, J.; Kuai, B.; et al. The transcription factor ZmNAC126 accelerates leaf senescence downstream of the ethylene signalling pathway in maize. Plant Cell Environ. 2020, 43, 2287-2300. [CrossRef]

34. Huysmans, M.; Buono, R.A.; Skorzinski, N.; Radio, M.C.; De Winter, F.; Parizot, B.; Mertens, J.; Karimi, M.; Fendrych, M.; Nowack, M.K. NAC Transcription Factors ANAC087 and ANAC046 Control Distinct Aspects of Programmed Cell Death in the Arabidopsis Columella and Lateral Root Cap. Plant Cell 2018, 30, 2197-2213. [CrossRef] [PubMed]

35. Gill, S.; Tuteja, N. Reactive oxygen species and antioxidant machinery in abiotic stress tolerance in crop plants. Plant Physiol. Biochem. 2010, 48, 909-930. [CrossRef] [PubMed]

36. Lindemose, S.; Jensen, M.K.; Van De Velde, J.; O'Shea, C.; Heyndrickx, K.S.; Workman, C.; Vandepoele, K.; Skriver, K.; De Masi, F. A DNA-binding-site landscape and regulatory network analysis for NAC transcription factors in Arabidopsis thaliana. Nucleic Acids Res. 2014, 42, 7681-7693. [CrossRef]

37. Jin, J.F.; Wang, Z.Q.; He, Q.Y.; Wang, J.Y.; Li, P.F.; Xu, J.M.; Zheng, S.J.; Fan, W.; Yang, J.L. Genome-wide identification and expression analysis of the NAC transcription factor family in tomato (Solanum lycopersicum) during aluminum stress. BMC Genom. 2020, 21, 1-14. [CrossRef]

38. Yao, W.; Li, C.; Lin, S.; Wang, J.; Zhou, B.; Jiang, T. Transcriptome analysis of salt-responsive and wood-associated NACs in Populus simonii $\times$ Populus nigra. BMC Plant Biol. 2020, 20, 317. [CrossRef]

39. Nuruzzaman, M.; Manimekalai, R.; Sharoni, A.M.; Satoh, K.; Kondoh, H.; Ooka, H.; Kikuchi, S. Genome-wide analysis of NAC transcription factor family in rice. Gene 2010, 465, 30-44. [CrossRef] [PubMed]

40. Zhao, C.-M.; Huang, X.-Q.; Yin, F.-Y.; Li, D.-Q.; Chen, Y.; Chen, L.; Cheng, Z.-Q. Research progress on NAC transcription factor family in Oryza sativa L. Plant Sci. J. 2020, 38, 278-287. [CrossRef]

41. Saidi, M.N.; Mergby, D.; Brini, F. Identification and expression analysis of the NAC transcription factor family in durum wheat (Triticum turgidum L. ssp. durum). Plant Physiol. Biochem. 2017, 112, 117-128. [CrossRef] [PubMed]

42. Fan, K.; Wang, M.; Miao, Y.; Ni, M.; Bibi, N.; Yuan, S.; Li, F.; Wang, X. Molecular Evolution and Expansion Analysis of the NAC Transcription Factor in Zea mays. PLoS ONE 2014, 9, e111837. [CrossRef]

43. Zhao, K.-G.; Zhou, M.-Q.; Chen, L.-Q.; Zhang, D.; Robert, G.W. Genetic Diversity and Discrimination of Chimonanthus praecox (L.) Link Germplasm Using ISSR and RAPD Markers. HortScience 2007, 42, 1144-1148. [CrossRef]

44. Liu, H.; Huang, R.; Ma, J.; Sui, S.; Guo, Y.; Liu, D.; Li, Z.; Lin, Y.; Li, M. Two C 3 H Type Zinc Finger Protein Genes, CpCZF1 and CpCZF2, from Chimonanthus praecox Affect Stamen Development in Arabidopsis. Genes 2017, 8, 199. [CrossRef]

45. Li, Z.; Jiang, Y.; Liu, D.; Ma, J.; Li, J.; Li, M.; Sui, S. Floral Scent Emission from Nectaries in the Adaxial Side of the Innermost and Middle Petals in Chimonanthus praecox. Int. J. Mol. Sci. 2018, 19, 3278. [CrossRef] 
46. Tian, J.; Ma, Z.; Zhao, K.; Zhang, J.; Xiang, L.; Chen, L. Transcriptomic and proteomic approaches to explore the differences in monoterpene and benzenoid biosynthesis between scented and unscented genotypes of wintersweet. Physiol. Plant. 2019, 166, 478-493. [CrossRef] [PubMed]

47. Huang, R.; Liu, D.; Ma, J.; Li, M.; Sui, S. CpWRKY71, a WRKY Transcription Factor Gene of Wintersweet (Chimonanthus praecox), Promotes Flowering and Leaf Senescence in Arabidopsis. Int. J. Mol. Sci. 2019, 20, 5325. [CrossRef] [PubMed]

48. Aslam, M.Z.; Lin, X.; Li, X.; Yang, N.; Chen, L. Molecular Cloning and Functional Characterization of CpMYC2 and CpBHLH13 Transcription Factors from Wintersweet (Chimonanthus praecox L.). Plants 2020, 9, 785. [CrossRef]

49. Zhao, R.; Song, X.; Yang, N.; Chen, L.; Xiang, L.; Liu, X.-Q.; Zhao, K. Expression of the subgroup IIIf bHLH transcription factor CpbHLH1 from Chimonanthus praecox (L.) in transgenic model plants inhibits anthocyanin accumulation. Plant Cell Rep. 2020, 39, 891-907. [CrossRef]

50. Liu, D.; Sui, S.; Ma, J.; Li, Z.; Guo, Y.; Luo, D.; Yang, J.; Li, M. Transcriptomic Analysis of Flower Development in Wintersweet (Chimonanthus praecox). PLoS ONE 2014, 9, e86976. [CrossRef]

51. Mohanta, T.K.; Yadav, D.; Khan, A.; Hashem, A.; Tabassum, B.; Khan, A.L.; Allah, E.F.A.; Al-Harrasi, A. Genomics, molecular and evolutionary perspective of NAC transcription factors. PLoS ONE 2020, 15, e0231425. [CrossRef]

52. Tran, L.-S.; Nakashima, K.; Sakuma, Y.; Osakabe, Y.; Qin, F.; Simpson, S.D.; Maruyama, K.; Fujita, Y.; Shinozaki, K.; YamaguchiShinozaki, K. Co-expression of the stress-inducible zinc finger homeodomain ZFHD1 and NAC transcription factors enhances expression of the ERD1 gene in Arabidopsis. Plant J. 2006, 49, 46-63. [CrossRef] [PubMed]

53. Mitsuda, N.; Matsui, K.; Ikeda, M.; Nakata, M.; Oshima, Y.; Nagatoshi, Y.; Ohme-Takagi, M. CRES-T, An Effective Gene Silencing System Utilizing Chimeric Repressors. Plant Transcr. Factors 2011, 754, 87-105.

54. Fang, Y.; Liao, K.; Du, H.; Xu, Y.; Song, H.; Li, X.; Xiong, L. A stress-responsive NAC transcription factor SNAC3 confers heat and drought tolerance through modulation of reactive oxygen species in rice. J. Exp. Bot. 2015, 66, 6803-6817. [CrossRef] [PubMed]

55. Lv, Z.; Wang, S.; Zhang, F.; Chen, L.; Hao, X.; Pan, Q.; Fu, X.; Li, L.; Sun, X.; Tang, K. Overexpression of a Novel NAC DomainContaining Transcription Factor Gene (AaNAC1) Enhances the Content of Artemisinin and Increases Tolerance to Drought and Botrytis cinereal in Artemisia annua. Plant Cell Physiol. 2016, 57, 1961-1971. [CrossRef]

56. Gunapati, S.; Naresh, R.; Ranjan, S.; Nigam, D.; Hans, A.; Verma, P.C.; Gadre, R.; Pathre, U.V.; Sane, A.P.; Sane, V.A. Expression of GhNAC2 from G. herbaceum, improves root growth and imparts tolerance to drought in transgenic cotton and Arabidopsis. Sci. Rep. 2016, 6, 24978. [CrossRef]

57. Hou, X.-M.; Zhang, H.-F.; Liu, S.-Y.; Wang, X.-K.; Zhang, Y.-M.; Meng, Y.-C.; Luo, D.; Chen, R.-G. The NAC transcription factor CaNAC064 is a regulator of cold stress tolerance in peppers. Plant Sci. 2020, 291, 110346. [CrossRef]

58. Jahan, A.; Harris, B.; Lowery, M.; Coburn, K.; Infante, A.M.; Percifield, R.J.; Ammer, A.G.; Kovinich, N. The NAC family transcription factor GmNAC42-1 regulates biosynthesis of the anticancer and neuroprotective glyceollins in soybean. BMC Genom. 2019, 20, 149. [CrossRef]

59. Yokotani, N.; Ichikawa, T.; Kondou, Y.; Matsui, M.; Hirochika, H.; Iwabuchi, M.; Oda, K. Tolerance to various environmental stresses conferred by the salt-responsive rice gene ONAC063 in transgenic Arabidopsis. Planta 2009, 229, 1065-1075. [CrossRef]

60. Yokotani, N.; Tsuchida-Mayama, T.; Ichikawa, H.; Mitsuda, N.; Ohme-Takagi, M.; Kaku, H.; Minami, E.; Nishizawa, Y. OsNAC111, a Blast Disease-Responsive Transcription Factor in Rice, Positively Regulates the Expression of Defense-Related Genes. Mol. Plant-Microbe Interact. 2014, 27, 1027-1034. [CrossRef]

61. Wang, F.; Wang, J.W.; Sun, L.J.; Song, X.S. The molecular cloning and functional characterization of ChNAC1, a NAC transcription factor in Cerasus humilis. Plant Growth Regul. 2019, 89, 331-343. [CrossRef]

62. Sun, D.; Zhang, X.; Zhang, Q.; Ji, X.; Jia, Y.; Wang, H.; Niu, L.; Zhang, Y. Comparative transcriptome profiling uncovers a Lilium regale NAC transcription factor, $\operatorname{LrNAC} 35$, contributing to defence response against cucumber mosaic virus and tobacco mosaic virus. Mol. Plant Pathol. 2019, 20, 1662-1681. [CrossRef] [PubMed]

63. Guan, H.; Liu, X.; Niu, F.; Zhao, Q.; Fan, N.; Cao, D.; Meng, D.; He, W.; Guo, B.; Wei, Y.; et al. OoNAC72, a NAC-Type Oxytropis ochrocephala Transcription Factor, Conferring Enhanced Drought and Salt Stress Tolerance in Arabidopsis. Front. Plant Sci. 2019, 10, 890. [CrossRef]

64. Negi, S.; Tak, H.; Ganapathi, T.R. Expression analysis of MusaNAC68 transcription factor and its functional analysis by overexpression in transgenic banana plants. Plant Cell Tissue Organ. Cult. (PCTOC) 2016, 125, 59-70. [CrossRef]

65. Mendes, G.C.; Reis, P.A.B.; Calil, I.P.; Carvalho, H.H.; Aragão, F.J.L.; Fontes, E.P.B. GmNAC30 and GmNAC81 integrate the endoplasmic reticulum stress- and osmotic stress-induced cell death responses through a vacuolar processing enzyme. Proc. Natl. Acad. Sci. USA 2013, 110, 19627-19632. [CrossRef] [PubMed]

66. Ezhang, L.N.; Ezhang, L.C.; Exia, C.; Ezhao, G.; Ejia, J.; Ekong, X.Y. The Novel Wheat Transcription Factor TaNAC47 Enhances Multiple Abiotic Stress Tolerances in Transgenic Plants. Front. Plant Sci. 2016, 6, 1174. [CrossRef]

67. Negi, S.; Tak, H.; Ganapathi, T.R. Overexpression of MusaNAC68 reduces secondary wall thickness of xylem tissue in banana. Plant Biotechnol. Rep. 2019, 13, 151-160. [CrossRef]

68. Li, X.-L.; Yang, X.; Hu, Y.-X.; Yu, X.-D.; Li, Q.-L. A novel NAC transcription factor from Suaeda liaotungensis K. enhanced transgenic Arabidopsis drought, salt, and cold stress tolerance. Plant Cell Rep. 2014, 33, 767-778. [CrossRef]

69. Mao, X.; Chen, S.; Li, A.; Zhai, C.; Jing, R. Novel NAC Transcription Factor TaNAC67 Confers Enhanced Multi-Abiotic Stress Tolerances in Arabidopsis. PLoS ONE 2014, 9, e84359. [CrossRef] 
70. Wang, Y.; Cao, S.; Guan, C.; Kong, X.; Cui, Y.; Liu, B.; Zhou, Y.; Zhang, Y. Overexpressing the NAC transcription factor LpNAC13 from Lilium pumilum in tobacco negatively regulates the drought response and positively regulates the salt response. Plant Physiol. Biochem. 2020, 149, 96-110. [CrossRef]

71. Kumar, S.; Stecher, G.; Tamura, K. MEGA7: Molecular Evolutionary Genetics Analysis Version 7.0 for Bigger Datasets. Mol. Biol. Evol. 2016, 33, 1870-1874. [CrossRef] [PubMed]

72. Livak, K.J.; Schmittgen, T.D. Analysis of relative gene expression data using real-time quantitative PCR and the $2^{-\Delta \Delta C T}$ Method. Methods 2001, 25, 402-408. [CrossRef]

73. Sui, S.; Luo, J.; Ma, J.; Zhu, Q.; Lei, X.; Li, M. Generation and Analysis of Expressed Sequence Tags from Chimonanthus praecox (Wintersweet) Flowers for Discovering Stress-Responsive and Floral Development-Related Genes. Comp. Funct. Genom. 2012, 2012, 1-13. [CrossRef] [PubMed]

74. Clough, S.J.; Bent, A. Floral dip: A simplified method for Agrobacterium-mediated transformation of Arabidopsis thaliana. Plant J. 1998, 16, 735-743. [CrossRef] [PubMed]

75. Dionisio-Sese, M.L.; Tobita, S. Antioxidant responses of rice seedlings to salinity stress. Plant Sci. 1998, 135, 1-9. [CrossRef]

76. Heath, R.L.; Packer, L. Photoperoxidation in isolated chloroplasts: I. Kinetics and stoichiometry of fatty acid peroxidation. Arch. Biochem. Biophys. 1968, 125, 189-198. [CrossRef] 